\title{
Simple and Practical Multigram Synthesis of D-Xylonate Using a Recombinant Xylose Dehydrogenase
}

\author{
Israel Sánchez-Moreno, ${ }^{* \dagger}$ Raúl Benito-Arenas, ${ }^{\ddagger}$ Pilar Montero-Calle, ${ }^{\ddagger} \S$ Carmen Hermida, \\ Eduardo García-Junceda, $*$, $*$ and Alfonso Fernández-Mayoralas** ${ }^{*}$ \\ †Venter Pharma S.L., Azalea 1, 28109 Alcobendas (Madrid), Spain \\ "Departamento de Química Bioorgánica, Instituto de Química Orgánica General (IQOG-CSIC), Juan de la Cierva 3, 28006 Madrid, \\ Spain
}

Supporting Information

ABSTRACT: An efficient multienzyme system for the preparative synthesis of D-xylonate, a chemical with versatile industrial applications, is described. The multienzyme system is based on D-xylose oxidation catalyzed by the xylose dehydrogenase from Calulobacter crescentus and the use of catalytic amounts of $\mathrm{NAD}^{+}$. The cofactor is regenerated in situ by coupling the reduction of acetaldehyde into ethanol catalyzed by alcohol dehydrogenase from Clostridium kluyveri.

Excellent conversions (>95\%) were obtained in a process that allows easy product isolation by simple evaporation of the volatile buffer and byproducts.

\section{INTRODUCTION}

In recent years, increasing energy costs and environmental concerns have led to increased awareness about plant biomass waste being a valuable feedstock for biorefining processes that give rise to platform chemicals. ${ }^{1}$ Carbohydrates account for 75 wt $\%$ of the plant biomass and can be harvested from a wide variety of biomass wastes and crops. ${ }^{2}$ The first platform chemicals in the biorefinery can be sugars composed of different five- and six-carbon monosaccharides. ${ }^{3}$ Glucose is the most widely used monosaccharide, which at present is industrially produced by the enzymatic hydrolysis of corn. ${ }^{4}$ On the other hand, sugar acids are useful chemical intermediates usually derived from the oxidation of common aldoses. The most well-known sugar acid is D-gluconate, and up to 87000 tons of it are produced annually worldwide. ${ }^{5}$ The increased demand for plant biomass feedstock has resulted in competition with food, higher prices, questionable land-use practices, and environmental concerns associated with their production. ${ }^{6}$ Therefore, numerous research efforts have focused on developing novel bioprocesses based on non-food renewable feedstock like hemicelluloses. ${ }^{7}$ A major plant hemicellulose of interest is xylan, a branched plant polysaccharide built of $\beta$-1,4-linked D-xylopyranosyl (Xylp) residues. In this sense, D-xylonate could serve as a substitute for D-gluconic acid with the advantage that D-xylose is a non-food sugar. D-Xylonate has found applications as a cement dispersant, ${ }^{8}$ for decreasing acrylamide contained in the food after cooking, ${ }^{9}$ in the production of co-polyamides, ${ }^{10}$ and as a precursor for 1,2,4-butanetriol synthesis. ${ }^{11,12}$ Recently, Dxylonic acid has also been used as a catalyst in a threecomponent reaction for the synthesis of pyrrole and xanthene derivatives with potential pharmaceutical properties. ${ }^{13}$

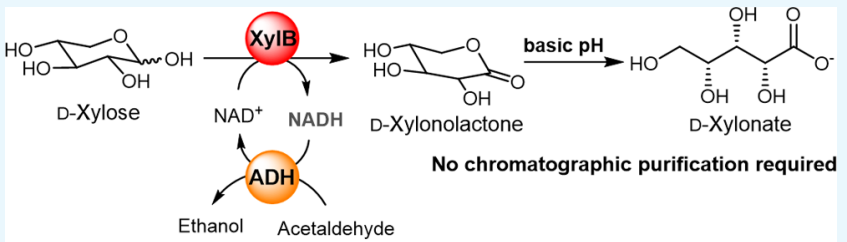

XylB $=$ Xylose Dehydrogenase ADH = Alcohol Dehydrogenase 
$\mathrm{XDH}$ from Hypocrea jecorina to produce and accumulate $\mathrm{D}$ xylonate. ${ }^{16,17}$ The same strategy was carried out employing the $\mathrm{D}-\mathrm{XDH}$ from Caulobacter crescentus (XylB). As this enzyme is more efficient for D-xylose oxidation, the production of $\mathrm{D}$ xylonate was greatly improved in the organisms modified with this gene. ${ }^{18-21}$ Further improvements of $\mathrm{D}$-xylonate production have been accomplished by addition of the lactonase $\mathrm{XylC}$ also from $C$. crescentus. ${ }^{22,23}$

The use of isolated enzymes can reduce some of the problems associated with whole-cell catalysts, such as the diffusion limitations or the isolation and purification of final products. The first attempt within this strategy was the use of commercial glucose oxidase for the synthesis of D-xylonate. ${ }^{24}$ However, the reaction requires a large amount of enzyme due to its low selectivity for D-xylose and the addition of catalase to decompose the hydrogen peroxide formed as a byproduct. In this way, the use of the $\mathrm{XylB}$ isolated from C. crescentus has been recently explored as a promising method to obtain Dxylonate. This enzyme was employed in an artificial fourenzyme complex, which allowed the formation of D-xylonate from hemicelluloses at a micromolar scale. ${ }^{25}$ This work proved that the XylB enzyme could be a good candidate for the preparative synthesis of $\mathrm{D}$-xylonate.

Recently, we have reported the overexpression in Escherichia coli of the XylB from C. crescentus NA 1000 and its isolation. ${ }^{26}$ The purified recombinant enzyme showed a strong preference for D-xylose against other assayed mono- and disaccharides as well as strong stability when stored as a freeze-dried powder with a half-life of at least 250 days both at $4{ }^{\circ} \mathrm{C}$ and at room temperature. In addition, more than $80 \%$ of the initial activity of the rehydrated freeze-dried enzyme remained after 150 days of incubation at $4{ }^{\circ} \mathrm{C}$. Considering these features, XylB is an excellent candidate for large-scale biocatalytic methods. For this reason, we decided to study the synthetic potential of this $\mathrm{D}$-xylose dehydrogenase for the preparative synthesis of $\mathrm{D}$ xylonate in a direct and simple way, as outlined in Scheme 2. A

Scheme 2. D-Xylose Dehydrogenase (XylB)-Catalyzed Synthesis of D-Xylonate with in Situ Regeneration of $\mathrm{NAD}^{+}$ Catalyzed by Alcohol Dehydrogenase (ADH) from $C$. kluyveri

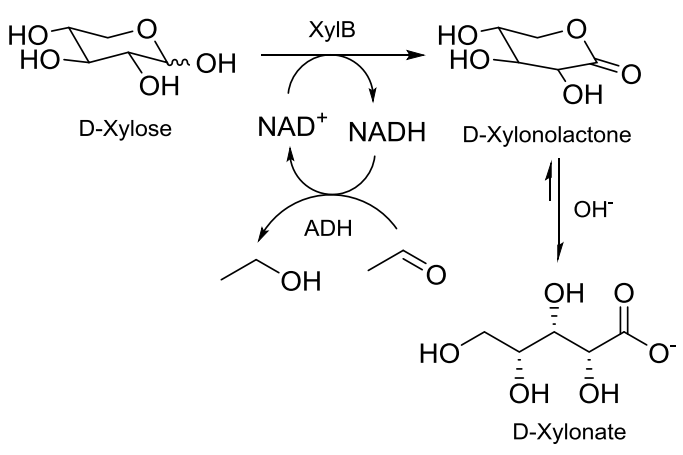

major drawback of this approach for large-scale production is that the enzyme requires an expensive cofactor, $\mathrm{NAD}^{+}$. To make practical and cheap the preparative enzymatic synthesis of D-xylonate, the development of a cofactor-regenerating system was explored.

For the in situ regeneration of $\mathrm{NAD}^{+}$, we employed an orthogonal cascade composed of the recombinant XylB from C. crescentus for xylose oxidation and the alcohol dehydrogenase $(\mathrm{ADH})$ from Clostridium kluyveri for $\mathrm{NAD}^{+}$recycling by the reduction of acetaldehyde to ethanol (Scheme 2). Here, we report our results on the synthesis of $\mathrm{D}$-xylonate by XylBcatalyzed oxidation of D-xylose.

\section{RESULTS AND DISCUSSION}

The reactions were performed in $\mathrm{NH}_{4} \mathrm{HCO}_{3}$ buffer $(10 \mathrm{mM}$, $\mathrm{pH}$ 8.0). The D-xylonic acid formed during the oxidation was continuously neutralized with $\mathrm{NaOH}$, and the $\mathrm{pH}$ of the medium was maintained constant during the reaction. The conversion rate in the enzymatic reaction is defined as the amount of D-xylose that is oxidized under the given reaction conditions per unit of time. The amount of substrate conversion to product was measured using a variant of the XylB activity assay, as described in the Experimental Section. This method has been previously optimized and described by us. $^{26}$ The percentage of conversion was calculated with respect to the initial amount of D-xylose, considering the limiting substrates in the optimization reactions. The efficiency of the enzymatic reactions was evaluated through their substrate conversion rates: elevated conversion rates indicate that the amount of accumulated product per unit of time is higher in a given reaction. Thus, the efficiency of different reaction conditions could be quantified and compared.

The incubation of D-xylose $(33 \mathrm{mM})$ with XylB (6 U), acetaldehyde (16 mol equiv), and alcohol dehydrogenase (35 $\mathrm{U})$ in $3 \mathrm{~mL}$ of buffer proceeded with complete conversion (entry 1, Table 1).

Table 1. Optimization of the $\mathrm{D}-\mathrm{Xylose} / \mathrm{CH}_{3} \mathrm{CHO}$ Ratio and $\mathrm{NAD}^{+}$Concentration

\begin{tabular}{cccc} 
entry & $\mathrm{D}$-xylose $/ \mathrm{CH}_{3} \mathrm{CHO}$ ratio & $\mathrm{NAD}^{+}(\mathrm{mM})$ & conversion (\%) \\
1 & $1: 16$ & 2.3 & 100 \\
2 & $1: 5$ & 2.3 & 100 \\
3 & $1: 3$ & 2.3 & 99 \\
4 & $1: 1.5$ & 2.3 & 95 \\
5 & $1: 3$ & 1.1 & 99 \\
6 & $1: 3$ & 0.83 & 99 \\
7 & $1: 3$ & 0.33 & 99 \\
8 & $1: 3$ & 0.16 & 98 \\
\hline
\end{tabular}

The system efficiency was so high that the D-xylose/ $\mathrm{CH}_{3} \mathrm{CHO}$ ratio could be reduced from $1: 16$ to $1: 1.5$ without significant loss in the percentage of conversion (entries 1-4, Table 1). The ratios $1: 3$ and $1: 1.5$ were chosen as optimal since the conversion was nearly quantitative. Interestingly, the $\mathrm{NAD}^{+}$concentration needed to feed the system could be reduced to $0.16 \mathrm{mM}$, just 2 times the $K_{\mathrm{M}}$ value of recombinant $\mathrm{XylB}$ for $\mathrm{NAD}^{+}, 25$ which corresponds to only $2 \%$ mol equiv (entry 8 , Table 1 ). The high efficiency of the $\mathrm{NAD}^{+}$recycling system, which works properly even when very low concentrations of the cofactor were employed to feed the system, is remarkable.

The synthesis of D-xylonate was optimized with respect to the xylose concentration (Table 2). Complete conversion was achieved at 33, 66, and $100 \mathrm{mM}$ although longer reaction times were required in a concentration-dependent manner. At 130 $\mathrm{mM}$, the transformation was not complete after $19 \mathrm{~h}$, probably because some enzyme inactivation took place.

It is especially remarkable that the D-xylose oxidation was also highly effective using a cell-free extract (CFE) from the recombinant strain of $E$. coli, which contains the overexpressed xylose dehydrogenase (entries 5-8, Table 2). Thus, similar 
Table 2. Optimization of the D-Xylose Concentration ${ }^{a}$

$\begin{array}{ccccc}\text { entry } & \text { XylB (units) } & \text { D-xylose }(\mathrm{mM}) & \text { reaction time }(\mathrm{h}) & \text { conversion (\%) } \\ 1 & 6 & 33 & 1 & 99 \\ 2 & 6 & 66 & 3.5 & 100 \\ 3 & 6 & 100 & 5 & 99 \\ 4 & 6 & 130 & 19 & 73 \\ 5^{b} & 6 & 33 & 1 & 100 \\ 6^{b} & 6 & 66 & 3.5 & 100 \\ 7^{b} & 13 & 100 & 2 & 100 \\ 8^{b} & 27 & 250 & 4 & 97\end{array}$

${ }^{a}$ Reactions were carried out in $3 \mathrm{~mL}$ of $\mathrm{NH}_{4} \mathrm{HCO}_{3}$ buffer $(10 \mathrm{mM}$, $\mathrm{pH}$ 8.0) containing $\mathrm{ADH}(35 \mathrm{U}), \mathrm{NAD}^{+}(0.33 \mathrm{mM})$, and acetaldehyde (3 equiv with respect to D-xylose). ${ }^{b}$ Cell-free extract (CFE) containing overexpressed xylose dehydrogenase was used as the catalyst.

results with both enzyme preparations were obtained at 33 and $100 \mathrm{mM}$ xylose concentrations. At the highest concentration, $250 \mathrm{mM}$, with additional enzyme and a long reaction time also, the conversion was excellent (entry 8 , Table 2). The decrease of the reaction rate and the final conversion at $130 \mathrm{mM}$ substrate (entry 4, Table 2) could be due to the accumulation of ethanol in the reaction media. In fact, the enzyme XylB seems to be very sensitive to the presence of high concentrations of ethanol (see Experimental Section).

We found that $\mathrm{pH}$ control is critical to avoid the formation of byproducts, particularly when the reactions were carried out at concentrations above $100 \mathrm{mM}$. In these cases, the appearance of new signals at $3-5 \mathrm{ppm}$ in the NMR spectra, which cannot be assigned to D-xylonate, were observed. The high-resolution mass spectra of the reaction mixtures contained the ion at $m / z 313.08$ (Figure S3) which is compatible with the chemical structure of a dixylonate monoester (Scheme 3).

Scheme 3. Chemical Structure of Dixylonate Monoester, which Derives from the Ring-Opening Reaction between a Molecule of D-Xylonolactone and a Hydroxyl of Xylonate

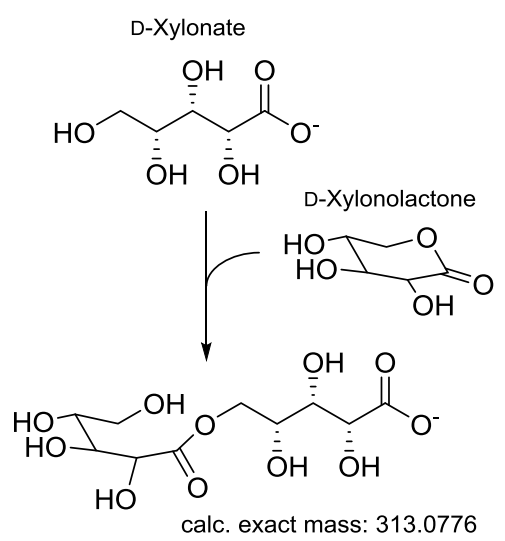

This compound must derive from the ring-opening reaction between xylonolactone and a hydroxyl of xylonate. Its formation was ascribed to a deficient basification during the progress of the reaction, thus leaving a high proportion of xylonolactone without being hydrolyzed and susceptible to being attacked by a hydroxyl nucleophile of another molecule, an intermolecular reaction that is favored at the highest concentrations. Considering these observations, the reactions were performed strictly maintaining the $\mathrm{pH}$ at 8.0. Under these conditions, the formation of byproducts was avoided and the reactions afforded pure D-xylonate.

Regarding the large-scale synthesis of D-xylonate, this approach has two important advantages: (i) it involves a volatile buffer, and both the substrate and the product of the $\mathrm{ADH}$-catalyzed reaction can be removed by evaporation, and (ii) the use of CFE containing XylB makes unnecessary the expensive purification of the enzyme. Optimization of the large-scale synthesis was carried out in three reactions where different amounts of D-xylose and CFE with overexpressed XylB were employed (Figure 1).

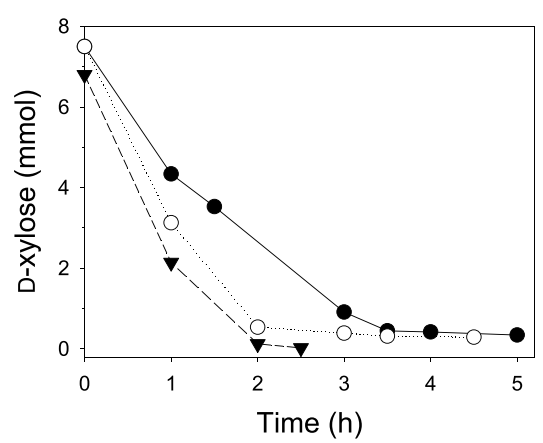

Figure 1. Optimization of the scaled-up reactions: $(\bullet), 0.25 \mathrm{mM} \mathrm{D}-$ xylose and $400 \mathrm{U}$ of XylB; (O), $0.25 \mathrm{mM}$ D-xylose and $610 \mathrm{U}$ of XylB; $(\boldsymbol{\nabla}), 0.22 \mathrm{mM}$ D-xylose and $610 \mathrm{U}$ of XylB.

When $0.25 \mathrm{mM}$ of D-xylose was used, reactions were not totally completed after $5 \mathrm{~h}$ of incubation: the highest achieved conversion of the substrate was $96 \%$, even when XylB was increased from 400 to $610 \mathrm{U}$. However, a small decrease in the D-xylose concentration from 0.25 to $0.22 \mathrm{mM}$ resulted in a quantitative oxidation after $3 \mathrm{~h}$ (Figure 1).

We carried out a gram-scale preparation of D-xylonate under these optimized reaction conditions. Since we obtained a total conversion of the substrate D-xylose (Figure S4), we decided to increase the scale of the reaction to $10 \mathrm{~g}$. Also, at this scale, the conversion of D-xylose to D-xylonate was practically quantitative. After the filtration of proteins and evaporation of the solvents, D-xylonate was obtained in pure form as indicated by its ${ }^{1} \mathrm{H}$ NMR spectrum (Figure 2). Therefore, the present twoenzyme system allowed us to quantitatively obtain $\mathrm{D}$-xylonate without the need of purification and using catalytic amounts of $\mathrm{NAD}^{+}$.

The concentration of xylose in the reaction was $33.3 \mathrm{~g} / \mathrm{L}$, which is similar to, or even higher than, that described in some fermentative processes. ${ }^{18}$ It is true that this substrate concentration is far from that of the most efficient fermentative methods (ref 18, 160-190 g/L), but the reaction time considerably decreases in the biocatalytical process: $2 \mathrm{~h}$ of reaction is enough to carry out a near quantitative reaction. Therefore, the conversion rate was much higher than that of any fermentative process described in the literature to date: $15.66 \mathrm{~g} /(\mathrm{L} \mathrm{h})$. This is more than 6 times better than that of the best of fermentation processes. ${ }^{18}$

Successive evaporations with water and ethanol were carried out to eliminate all of the solvents present in the sample and derive an accurate yield value of the xylonate obtained. However, a single evaporation would be enough to obtain a wet but still very pure xylonate, which could contain some ammonium salt. We would like to highlight that this is the first multigram synthesis of xylonate, where the final yield is 


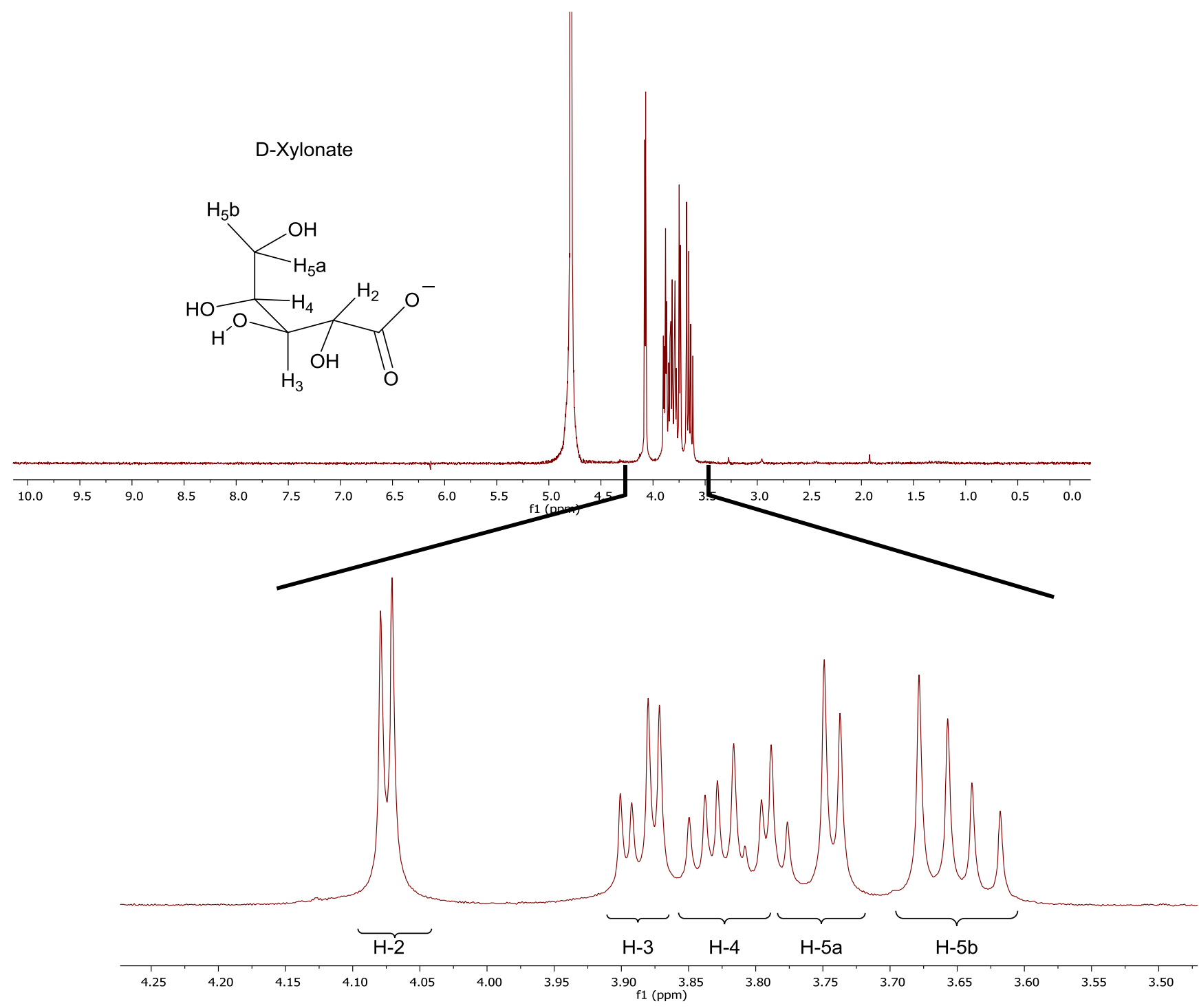

Figure 2. ${ }^{1} \mathrm{H}$ NMR spectrum of the concentrated reaction mixture containing D-xylose $(10 \mathrm{~g}, 220 \mathrm{mM})$, $\mathrm{NAD}^{+}(0.33 \mathrm{mM})$, acetaldehyde $(330$ $\mathrm{mM})$, CFE containing overexpressed $\mathrm{XylB}(6500 \mathrm{U})$, and $\mathrm{ADH}(3600 \mathrm{U})$ in $\mathrm{NH}_{4} \mathrm{HCO}_{3}$ buffer $(10 \mathrm{mM}, \mathrm{pH} 8.0)$.

calculated as the mass of the pure product and not on basis of xylose conversion in the fermentation process. In addition, fermentation processes usually quantify both intra- and extracellular accumulated xylonate.

\section{CONCLUSIONS}

In this work, we present a biocatalytic cascade for producing $\mathrm{D}$ xylonate based on the use of xylose dehydrogenase from Caulobacter crescentus and an efficient cofactor regeneration method employing the enzyme $\mathrm{ADH}$ from Clostridium kluyveri. One important advantage of this system is that the buffer and both the substrate and the product of the $\mathrm{ADH}$-catalyzed reaction are volatile, allowing, after complete conversion, an easy work-up and isolation of the product. In addition, the use of $\mathrm{CFE}$ containing $\mathrm{XylB}$ makes unnecessary the expensive purification of the enzyme. This process has been easily scaled up to 10 gram-size reactions. We believe that this biocatalytic procedure provides a new path to D-xylonic acid production, competitive with the fermentative processes currently used. The optimized methodology for oxidation and cofactor regeneration presented in this work could also be applied to the synthesis of different aldonic sugars, if XylB were replaced by other dehydrogenases with alternative substrate specificities and scopes.

\section{EXPERIMENTAL SECTION}

General Information. Xylose dehydrogenase from $C$. crescentus NA 1000 (XylB) was produced in our lab as previously described. ${ }^{26}$ Alcohol dehydrogenase from C. kluyveri was purchased from Sigma-Aldrich. All other chemicals were purchased from commercial sources as reagent grade. IR spectra were obtained in FT-IR Spectrum One. The frequency of absorption maximums $(\nu)$ is expressed in $\mathrm{cm}^{-1}$ and the samples were analyzed in a $\mathrm{KBr}$ tablet. UV spectra were acquired on Molecular Devices Spectramax PLUS 384. Highresolution mass spectra (HRMS) were recorded on an Agilent 6520 Accurate Mass Q-TOF spectrometer with an ESI source. ${ }^{1} \mathrm{H}$ and ${ }^{13} \mathrm{C}$ NMR spectra, using $\mathrm{D}_{2} \mathrm{O}$ as the solvent, were recorded on a Varian System 500 spectrometer equipped with a $5 \mathrm{~mm} \mathrm{HCN}$ cold probe with field z-gradient, operating at 500.13 and $125.76 \mathrm{MHz}$ for ${ }^{1} \mathrm{H}$ and ${ }^{13} \mathrm{C}$, respectively. The sample temperature was maintained constant at $298 \mathrm{~K}$. 
Enzyme Activity Assays. XylB enzyme activity was monitored by spectrophotometric measurement of the $\mathrm{NADH}$ formed from cofactor reduction. Variations of absorbance at $340 \mathrm{~nm}$ are proportional to the D-xylose concentration consumed in the reaction $\left(\varepsilon_{\mathrm{NADH}}=6220 \mathrm{~cm}^{-1}\right.$ $\left.\mathrm{M}^{-1}\right)$. Reaction mixtures of $1 \mathrm{~mL}$ contained $\mathrm{NaH}_{2} \mathrm{PO}_{4}(50$ $\mathrm{mM}, \mathrm{pH} 8.0), \mathrm{NAD}^{+}(0.5 \mu \mathrm{mol})$, D-xylose $(5 \mu \mathrm{mol})$, and the enzyme sample $(0.2-0.5 \mu \mathrm{g}$ protein). Activity assays were performed at $25{ }^{\circ} \mathrm{C}$. One unit (U) of XylB activity was defined as the amount that produces $1 \mu \mathrm{mol}$ of $\mathrm{D}$-xylonolactone per minute under the above conditions.

Tracking of the Reaction Progress. The amount of Dxylose consumed in the reaction was followed by the enzymatic quantification assay described above, with slight modifications. Aliquots of $20 \mu \mathrm{L}$ from the reaction mixture were collected over time and quenched with $7 \% \mathrm{HClO}_{4}(1: 5 \mathrm{v} / \mathrm{v})$ and $10 \%$ $\mathrm{NaOH}(1: 5 \mathrm{v} / \mathrm{v})$. Detection of $\mathrm{D}$-xylose was performed in 1 $\mathrm{mL}$ reactions containing $\mathrm{NaH}_{2} \mathrm{PO}_{4}$ buffer $(50 \mathrm{mM}, \mathrm{pH} 8.0)$, $\mathrm{NAD}^{+}(0.5 \mu \mathrm{mol}, 0.5 \mathrm{mM})$, XylB $(0.45 \mathrm{U}, 15 \mu \mathrm{g}$ of protein), and a quenched aliquot (between 1 and $2.5 \mu \mathrm{L}$ ). Variation of absorbance at $340 \mathrm{~nm}\left(\Delta \mathrm{Abs}_{340 \mathrm{~nm}}\right)$ before and after XylB addition was used to calculate the final $\mathrm{D}$-xylose concentration (Figure S1).

Optimization of the D-Xylonate Synthesis. Small-scale reactions for optimization of the synthesis parameters were carried out in $3 \mathrm{~mL}$ of $\mathrm{NH}_{4} \mathrm{HCO}_{3}$ buffer ( $10 \mathrm{mM}, \mathrm{pH} 8.0$ ) containing the enzymes $\mathrm{XylB}(6 \mathrm{U})$ and $\mathrm{ADH}(35 \mathrm{U})$ and different final concentrations and ratios of the reagents $\mathrm{D}$ xylose, $\mathrm{NAD}^{+}$, and $\mathrm{CH}_{3} \mathrm{CHO}$. Initially, the effects of four different $\mathrm{D}$-xylose $/ \mathrm{CH}_{3} \mathrm{CHO}$ ratios (1:16, 1:5, 1:3, and 1:1.5) on the reaction efficiencies was assessed (Table 1 ). The effect of decreasing the cofactor concentration was examined in five reactions carried out at different $\mathrm{NAD}^{+}$concentrations (2.3, $1.1,0.83,0.33$, and $0.16 \mathrm{mM}$ ) using a $\mathrm{D}$-xylose $/ \mathrm{CH}_{3} \mathrm{CHO}$ ratio of $1: 3$ ( 0.33 and $0.99 \mathrm{mM}$, respectively) (Table 1$)$. The optimization of the final D-xylose concentration was tested in five reactions conducted at increasing concentrations of this substrate $(33,66,100,130$, and $250 \mathrm{mM})$ and 3 equiv of $\mathrm{CH}_{3} \mathrm{CHO}$, employing a $\mathrm{NAD}^{+}$concentration of $0.33 \mathrm{mM}$ (Table 2). The biotransformation using CFE as the source of the XylB enzyme was examined by a repetition of two of the Dxylose optimization reactions (carried out with 33 and 66 $\mathrm{mM}$ ), but employing CFE instead of pure $\mathrm{XylB}$, to compare the obtained results (Table 2). In addition, two larger-scale reactions were carried out under similar conditions using both CFE containing XylB and pure enzyme (Figure S2). Finally, the optimal D-xylose/XylB ratio in reactions employing $\mathrm{CFE}$ as the catalyst was studied in four reactions with increasing amounts of D-xylose $(33,66,100$, and $250 \mathrm{mM})$ and XylB (6, 6 , 13, and $27 \mathrm{U}$, respectively) (Table 2). A more detailed description of the procedures used in every optimization step can be found in the Supporting Information.

Scale up of the synthesis of D-Xylonate to $10 \mathrm{~g}$. The optimized preparative reaction was carried out in $300 \mathrm{~mL}$ of $\mathrm{NH}_{4} \mathrm{HCO}_{3}$ buffer $(10 \mathrm{mM}, \mathrm{pH} 8.0)$ containing $10 \mathrm{~g}$ of $\mathrm{D}-$ xylose (66.6 mmol, $220 \mathrm{mM}), 1.5$ equiv of $\mathrm{CH}_{3} \mathrm{CHO}(100$ mmol, $330 \mathrm{mM}), 40 \mathrm{~mL}$ of CFE with overexpressed XylB $(162.5 \mathrm{U} / \mathrm{mL}$; total activity $6500 \mathrm{U})$, alcohol dehydrogenase (12 mg; $3600 \mathrm{U})$, and $\mathrm{NAD}^{+}(100 \mu \mathrm{mol}, 0.33 \mathrm{mM})$. The reaction was initiated by the addition of $\mathrm{NAD}^{+}$. The $\mathrm{pH}$ of the reaction mixture was continuously adjusted to 8.0 by the addition of a concentrated solution of $\mathrm{NaOH}(8 \mathrm{M})$ and maintained until no progressive acidification was observed.
The protein present in the reaction mixture was precipitated by the addition of ethanol $(300 \mathrm{~mL}, 1 \mathrm{vol})$ and removed by centrifugation $\left(9000 \times g, 5 \mathrm{~min}\right.$ at $\left.4{ }^{\circ} \mathrm{C}\right)$. The supernatant was transferred to a $500 \mathrm{~mL}$ round-bottom flask and completely evaporated (rotary evaporator). To ensure that all of the volatile compounds were removed, successive additions and evaporations of Milli- $Q$ water (four times, $30 \mathrm{~mL}$ each) were performed. The residue was suspended in $5 \mathrm{~mL}$ of Milli-Q water and filtered to eliminate residues of the precipitated protein (filter Whatman $0.2 \mu \mathrm{m}$, Milipore). The filtrate was freeze-dried to obtain D-xylonate as a hygroscopic white foam $(16.150 \mathrm{~g})$. The product obtained was dissolved in hot $\mathrm{EtOH}$ $(50 \mathrm{~mL})$, and later the solvent was removed under reduced pressure (three times). Additionally, the product was dried at $50{ }^{\circ} \mathrm{C}$ under reduced pressure over $5 \mathrm{~h}$ to obtain $\mathrm{D}$-xylonate as a yellowish solid $(11.710 \mathrm{~g})$. The amount of D-xylonate obtained corresponds to a yield of $94 \%$, considering that the sodium salt of the acid coordinated with 0.45 water molecules (see below the elemental analysis). $[\alpha]_{\mathrm{D}}:+15.0^{\circ}$ (c 1.0, water). IR (KBr): 3420, 2936, 1606, 1415, 1126, 1089, $720 \mathrm{~cm}^{-1} \cdot{ }^{1} \mathrm{H}$ NMR (300 MHz, $\left.\mathrm{D}_{2} \mathrm{O}\right): \delta 4.01(\mathrm{~d}, J=2.5 \mathrm{~Hz}, 1 \mathrm{H}), 3.82(\mathrm{dd}, J$ $=6.3,2.5 \mathrm{~Hz}, 1 \mathrm{H}), 3.75(\mathrm{td}, J=6.4,3.7 \mathrm{~Hz}, 1 \mathrm{H}), 3.69(\mathrm{dd}, J=$ 11.9, $3.7 \mathrm{~Hz}, 1 \mathrm{H}), 3.58(\mathrm{dd}, J=11.9,6.5 \mathrm{~Hz}, 1 \mathrm{H}) .{ }^{13} \mathrm{C}$ NMR $\left(100 \mathrm{MHz}, \mathrm{D}_{2} \mathrm{O}\right): \delta$ 178.49, 72.76, 72.74, 72.41, 62.43. HRMS $\left(\mathrm{ESI}^{-}\right) \mathrm{m} / z$ (calcd 165.0399): $165.0401[\mathrm{M}-\mathrm{H}]^{-}$. Anal. calcd for $\mathrm{C}_{5} \mathrm{H}_{9} \mathrm{O}_{6} \mathrm{Na} \cdot 0.45 \mathrm{H}_{2} \mathrm{O}: \mathrm{C}, 30.61 ; \mathrm{H}, 5.09$, found: $\mathrm{C}$, 30.13; H, 4.79.

\section{ASSOCIATED CONTENT}

\section{S Supporting Information}

The Supporting Information is available free of charge on the ACS Publications website at DOI: 10.1021/acsomega.9b01090.

Optimization of D-xylonate synthesis; materials, experimental descriptions, and analytical methods (PDF)

\section{AUTHOR INFORMATION}

\section{Corresponding Authors}

*E-mail: isanchez@venterpharma.com (I.S.-M.).

*E-mail: eduardo.junceda@csic.es (E.G.-J.).

*E-mail: alfonso.mayoralas@csic.es (A.F.-M.).

\section{ORCID}

Eduardo García-Junceda: 0000-0002-2344-8743

\section{Present Address}

${ }^{\S}$ Centro de investigación Médica Aplicada (CIMA), Instituto de Investigación Sanitaria de Navarra, Universidad de Navarra, Avenida Pio XII 55, 31008 Pamplona, Spain (P.M.-C.).

\section{Author Contributions}

I.S.-M. and A.F.-M. conceived and designed the study. I.S.-M., R.B.-A., and P.M.-C. performed the experiments. I.S.-M., E.G.J., and A.F.-M. supervised the work and analyzed and interpreted the results. The manuscript was written through contributions of all authors. All authors have given approval to the final version of the manuscript.

Notes

The authors declare no competing financial interest.

\section{ACKNOWLEDGMENTS}

This work was partially supported by the grant MAT201565184-C2-2-R (MINECO/FEDER). We thank the referees for their helpful comments. 


\section{REFERENCES}

(1) Kwapinski, W.; Byrne, C. M. P.; Kryachko, E.; Wolfram, P.; Adley, C.; Leahy, J. J.; Novotny, E. H.; Hayes, M. H. B. Biochar from biomass and waste. Waste Biomass Valorization 2010, 1, 177-189.

(2) Chatterjee, C.; Pong, F.; Sen, A. Chemical conversion pathways for carbohydrates. Green Chem. 2015, 17, 40-71.

(3) Isikgor, F. H.; Becer, C. R. Lignocellulosic biomass: a sustainable platform for the production of bio-based chemicals and polymers. Polym. Chem. 2015, 6, 4497-4559.

(4) Koutinas, A.; Du, C.; Wang, R. H.; Webb, C. In Introduction to Chemicals from Biomass; Clark, J. H., Deswarte, F., Eds.; John Wiley \& Sons Inc.: Hoboken, 2008; Chapter 4.

(5) Sauer, M.; Porro, D.; Mattanovich, D.; Branduardi, P. Microbial production of organic acids: expanding the markets. Trends Biotechnol. 2008, 26, 100-108.

(6) Hill, J.; Nelson, E.; Tilman, D.; Polasky, S.; Tiffany, D. Environmental, economic, and energetic costs and benefits of biodiesel and ethanol biofuels. Proc. Natl. Acad. Sci. U.S.A. 2006, 103, 11206-11210.

(7) Alonso, S.; Rendueles, M.; Díaz, M. Microbial production of specialty organic acids from renewable and waste materials. Crit. Rev. Biotechnol. 2015, 35, 497-513.

(8) Chun, B.-W.; Dair, B.; Macuch, P. J.; Wiebe, D.; Porteneuve, C.; Jeknavoriani, A. The development of cement and concrete additive. Appl. Biochem. Biotechnol. 2006, 129-132, 645-658.

(9) Tornoda, Y.; Hanaoka, A.; Yasuda, T.; Takayama, T.; Hiwatashi, A. Method of Decreasing Acrylamide in Food Cooked under Heat. U.S. Patent US20040131737A1, 2004.

(10) Zamora, F.; Bueno, M.; Molina, I.; Iribarren, J. I.; MuñozGuerra, S.; Galbis, J. A. Stereoregular copolyamides derived from Dxylose and L-arabinose. Macromolecules 2000, 33, 2030-2038.

(11) Valdehuesa, K. N. G.; Liu, H.; Ramos, K. R. M.; Park, S. J.; Nisola, G. M.; Lee, W.-K.; Chung, W.-J. Direct bioconversion of Dxylose to 1,2,4-butanetriol in an engineered Escherichia coli. Process Biochem. 2014, 49, 25-32.

(12) Niu, W.; Molefe, M. N.; Frost, J. W. Microbial Synthesis of the Energetic Material Precursor 1,2,4-Butanetriol. J. Am. Chem. Soc. 2003, 125, 12998-12999.

(13) Ma, J.; Zhong, L.; Peng, X.; Sun, R. D-Xylonic acid: a solvent and an effective biocatalyst for a three-component reaction. Green Chem. 2016, 18, 1738-1750.

(14) Fuente-Hernández, A.; Corcos, P.-O.; Beauchet, R.; Lavoie, J.M. In Liquid, Gaseous and Solid Biofuels - Conversion Techniques; Fang, Z., Ed.; InTech: Rijeka, 2013; Chapter 1.

(15) Toivari, M. H.; Nygård, Y.; Penttilä, M.; Ruohonen, L.; Wiebe, M. G. Microbial d-xylonate production. Appl. Microbiol. Biotechnol. 2012, 96, 1-8.

(16) Nygård, Y.; Toivari, M. H.; Penttilä, M.; Ruohonen, L.; Wiebe, M. G. Bioconversion of d-xylose to d-xylonate with Kluyveromyces lactis. Metab. Eng. 2011, 13, 383-391.

(17) Toivari, M. H.; Ruohonen, L.; Richard, P.; Penttilä, M.; Wiebe, M. G. Saccharomyces cerevisiae engineered to produce D-xylonate. Appl. Microbiol. Biotechnol. 2010, 88, 751-760.

(18) Zhang, Y.; Guo, S.; Wang, Y.; Liang, X.; Xu, P.; Gao, C.; Ma, C. Production of D-Xylonate from Corn Cob hydrolysate by a metabolically engineered Escherichia coli strain. ACS Sustainable Chem. Eng. 2019, 7, 2160-2168.

(19) Toivari, M. H.; Vehkomäki, M.-L.; Nygård, Y.; Penttilä, M.; Ruohonen, L.; Wiebe, M. G. Low $\mathrm{pH}$ d-xylonate production with Pichia kudriavzevii. Bioresour. Technol. 2013, 133, 555-562.

(20) Toivari, M.; Nygard, Y.; Kumpula, E. P.; Vehkomaeki, M.-L.; Bencina, M.; Valkonen, M.; Maaheimo, H.; Andberg, M.; Koivula, A.; Ruohonen, L.; Penttilae, M.; Wiebe, M. G. Metabolic engineering of Saccharomyces cerevisiae for bioconversion of d-xylose to D-xylonate. Metab. Eng. 2012, 14, 427-436.

(21) Liu, H.; Valdehuesa, K. N.; Nisola, G. M.; Ramos, K. R. M.; Chung, W.-J. High yield production of d-xylonic acid from d-xylose using engineered Escherichia coli. Bioresour. Technol. 2012, 115, 244248.
(22) Nygård, Y.; Maaheimo, H.; Mojzita, D.; Toivari, M.; Wiebe, M. G.; Resnekov, O.; Pesce, C. G.; Ruohonen, L.; Penttilä, M. Single cell and in vivo analyses elucidate the effect of xylC lactonase during production of D-xylonate in Saccharomyces cerevisiae. Metab. Eng. 2014, 25, 238-247.

(23) Cao, Y.; Xian, M.; Zou, H.; Zhang, H. Metabolic Engineering of Escherichia coli for the Production of Xylonate. PLoS One 2013, 8, No. e67305.

(24) Pezzotti, F.; Therisod, M. Enzymatic synthesis of aldonic acids. Carbohydr. Res. 2006, 341, 2290-2292.

(25) Lee, C. C.; Kibblewhite, R. E.; Paavola, C. D.; Orts, W. J.; Wagschal, K. Production of D-xylonic acid from hemicellulose using artificial enzyme complexes. J. Microbiol. Biotechnol. 2017, 27, 77-83.

(26) Sánchez-Moreno, I.; García-Junceda, E.; Hermida, C.; Fernández-Mayoralas, A. Development of a new method for D-xylose detection and quantification in urine, based on the use of recombinant xylose dehydrogenase from Caulobacter crescentus. J. Biotechnol. 2016, $234,50-57$ 